\title{
Chlorsiliconorganic Compound Formed during Lipid Separation from Japan Marine Ascidia
}

\author{
S. V. Isay ${ }^{1}$, N. G. Busarova1, L. A. Zemnuhova ${ }^{2}$ \\ ${ }^{1}$ Pacific Institute of Bioorganic Chemistry of DVO of the Russian Academy of Sciences, Vladivostok, Russia \\ ${ }^{2}$ Institute of Chemistry of DVO of the Russian Academy of Sciences, Vladivostok, Russia \\ Email: "isai@piboc.dvo.ru
}

Received 24 May 2015; accepted 19 July 2015; published 23 July 2015

Copyright (C) 2015 by authors and Scientific Research Publishing Inc.

This work is licensed under the Creative Commons Attribution International License (CC BY).

http://creativecommons.org/licenses/by/4.0/

(c) (i) Open Access

\section{Abstract}

The crystal substance has been isolated from chloroform-ethanol extract of sea organism Halocynthia aurantium. A set of spectrometry methods was used to describe a structure of this compound. It was appeared that element analysis showed $\approx 60 \%$ chlorine, less silicon, carbon and hydrogen. Another spectroscopy method (UV, IR, NMR) did not give an additional information. The data obtained suggests us that we have the matter with unusual compound. X-ray-phase analysis was used also. On the basis of an element analysis and $X$-ray diffraction parameters the formula of compound $\mathrm{C}_{2} \mathrm{H}_{2} \mathrm{Si}_{4} \mathrm{Cl}_{12}$ has been offered.

\section{Keywords}

Marine Organism Halocynthia aurantium, Crystal, Chlorosiliconorganic Compound

\section{Introduction}

Our interest to ascidia has been determined by the attempts to study the lipids of these group of sea animals, in particularly fatty acids (FA) and prostaglandins (PG). Earlier we have shown that extracts from H. aurantium possess high PG-like activity [1].

Being engaged in research lipids from sea organisms, we have found out that at storage lipid fractions crystals are formed, in the course of storage crystals grow. This fact has interested us, and we investigated structure of one of them and some properties of crystal compound.

The element analysis has shown that a crystal contents to $60 \%$ of chlorine, $12 \%$ of silicon and $1 \%$ of carbon.

\footnotetext{
${ }^{*}$ Corresponding author.
}

How to cite this paper: Isay, S.V., Busarova, N.G. and Zemnuhova, L.A. (2015) Chlorsiliconorganic Compound Formed during Lipid Separation from Japan Marine Ascidia. Open Journal of Marine Science, 5, 290-294. 
On these preliminary data it became clear, that we deal with silicon organic compound.

The chemistry and properties of siliconorganic compounds were devoted a lot of literature because they are widely used in medical practice [2]-[8].

However, as to data about the derivatives of silicon organic compounds and in particularly chlorosilanes chemical information appears to be rather scanty [9]-[12].

The purpose of our research was to study structure of the unusual compound formed during prostaglandins separation from sea organism $H$. aurantium.

The chemistry of silicon and its compounds is extremely dynamic. Hardly any technology in recent decades has shaped technical progress so strikingly as silicon chemistry. This success story begins with the element silicon. In nature, silicon occurs exclusively in oxidized form, as the compounds silicon dioxide and silicates. Silicon is the second commonest element in the Earth's solid crust, accounting for 25.8 percent by weight, and the most important component of inorganic materials. Since silicon is very rarely found as an element in nature, it was not isolated until relatively recently. On the other hand, siliceous construction and engineering materials, such as sand, clay and ceramics, have been available since time immemorial.

It is not necessary to confuse terms: silicon (element) and derivative silicon-silicone (polymer, silanes).

Silicon plays an essential role in bone formation and maintenance. Silicon improves bone matrix quality and facilitates bone mineralization. Silicon supplementation in animals and humans has been shown to increase bone mineral density and improve bone strength. Dietary sources of bioavailable silicon include whole grains, cereals, beer, and some vegetables such as green beans. Silicon in the form of silica, or silicon dioxide $\left(\mathrm{SiO}_{2}\right)$, is a common food additive but has limited intestinal absorption. More attention to this important mineral by the academic community may lead to improved nutrition, dietary supplements, and better understanding of the role of silicon in the management of postmenopausal osteoporosis [6] [7].

Organosilicon compounds are widely encountered in commercial products. Most common are sealants, caulks, adhesives, and coatings made from silicones.

Silicone caulk, commercial sealants, is mainly composed of organosilicon compounds.

It is impossible to describe within the limits of article all properties of chlorosiliconorganic compounds and their applications. They are used in everyday lives. It is enough to look through encyclopedia.

\section{Experimental Section}

Animal material. $H$. aurantium were collected in april at a Troiza bay of Peter the Great bay of Japan sea. The sample of Ascidia were homogenized and extracted by 1.5 liters mixture of solvents $\mathrm{CHCl}_{3}-\mathrm{EtOH}(1: 1)$. Further extraction of this material was carried out, taking into account on $20 \mathrm{~g}$ of the crushed tissue on $100 \mathrm{ml}$ mixture of solvents.

Extraction and separation. 3-fold extraction procedure was carried out by mixture $\mathrm{CHCl}_{3}$-EtOH (1:1). Solvent after everyone extraction was evaporated up to the minimal volume by the rotor evaporator. The first extract contained very much aqueous solution. The bottom chloroform layer was collected after phases separation. Repeated extraction by the extraction mixture also was given the extract contained water, but to a lesser degree. A chloroform extract has dark cherry-color. The crystals fall at solvent evaporation of this last (third) extraction procedure.

The total content of organic substance after 3 extractions has made $1.93 \%$ on a tissue.

Used devices. The element analysis is performed with using an atom-adsorption spectrometer (AA-240, Perkin Elmer, Germany), nuclear-quadrupole resonance (YaKR), difractogramma (DPOU-2, 1Cu monochromator, J $=30 \mathrm{ma}, \mathrm{V}=30 \mathrm{kv}, 44 \mathrm{~min}, 2400 \mathrm{~mm} / \mathrm{h}, 1000 \mathrm{imp} / \mathrm{sec})$.

X-ray-phase analysis has performed, using x-ray chamber WBG 2 (VEB Freiberger Prazisions Mechanic), with diameter of the cylindrical cartridge $57.3 \mathrm{~mm}$; CuK-radiation, filtrated by nickel.

\section{Results and Discussion}

A monocrystal (sizes are $25 \times 21 \mathrm{~mm}$, thickness is $2 \mathrm{~mm}$; it has shown at the Figure 1 ) has obtained from chloroform-ethanol extract of $H$. aurantium at lipid separation. Under a microscope the crystal represents volumetric structure as the layered plates similar to mica. On edges it has a dark fringing. The crystal gets silver spice (metal shine) under a microscope at different illumination of a field.

The monocrystal has been crushed for carrying out of analyses. Melting point of a substance has been mea- 


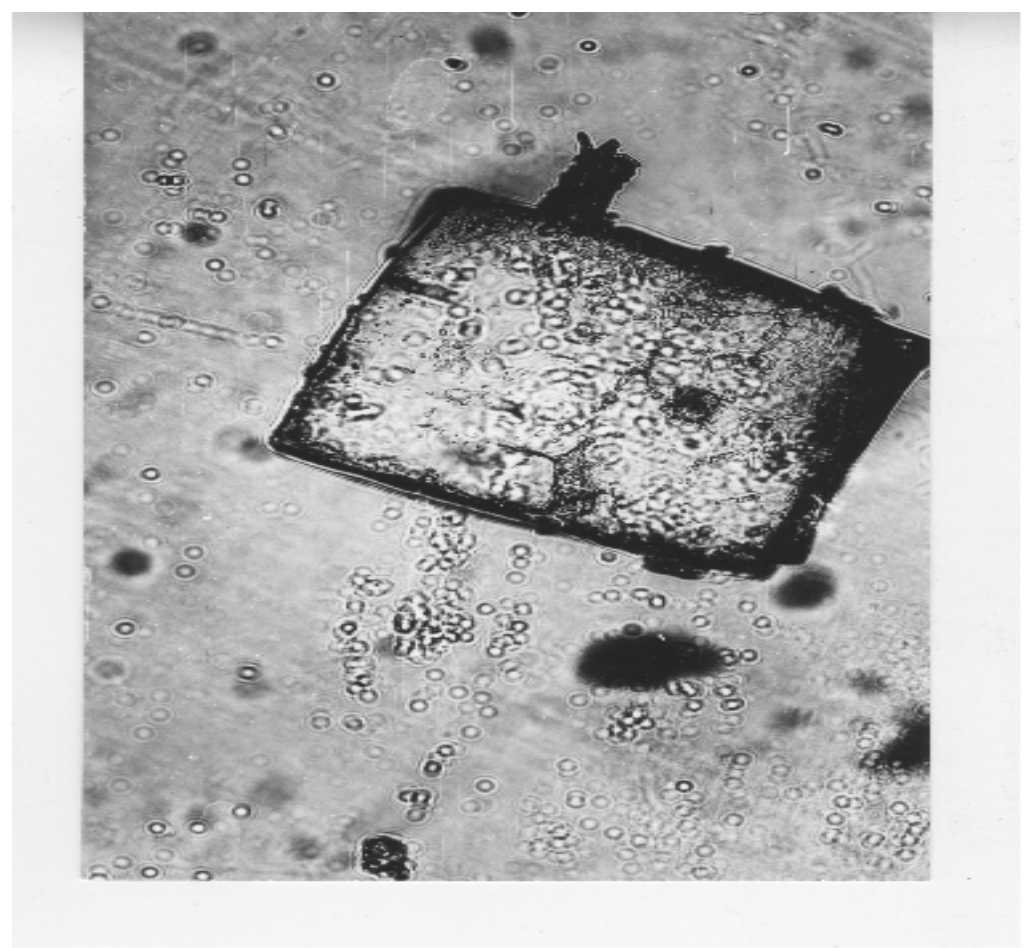

Figure 1. A crystal separated from an extract of Japan sea ascidia Halocynthia aurantium Photo have done under the microscope (Jenaval, Carl Zeis, Vienna); lens $2.5 \mathrm{~mm} \times 50$; rise 2:1.

sured to be $170^{\circ} \mathrm{C}$.

The substance appeared to be rather unstable: it has evaporated slowly in the open air without any residue.

The crystals do not soluble in water, chloroform, diethyl ether. They are soluble in aqueous ethanol and ipropyl alcohol. By element analysis has found (\%): C 1.00, H 0.20, Cl 59.00.

The neutronic activation analysis has shown (\%): Si 12.00, Al 0.30 and traces Br, Y, Zr. The atomic-emission analysis has confirmed high percent of chlorine and has shown the trace amounts of $\mathrm{Al}, \mathrm{Ba}, \mathrm{Br}, \mathrm{Ca}, \mathrm{Mg}, \mathrm{Fe}, \mathrm{Sr}$, $\mathrm{Zr}, \mathrm{Y}$.

X-ray-phase analysis (RPA) has shown, the substance investigated has a crystal structure. Diffractogram data of a compound obtained are presented in Table 1. The crystal isolated according to RPA data is Isostructures of $\mathrm{RbCl}$ and $\mathrm{KCl}$ compounds and it belongs to cubic syngonia (crystallographic system) with parameters $\mathrm{a}=\mathrm{b}=\mathrm{c}$ $=6.59 \AA$.

Chlorosilicon organic compounds of an animal origin is not investigated practically. Despite of use of several spectroscopic methods (UV, IR, ${ }^{13} \mathrm{C}-\mathrm{NMR}$ ), the most informative methods to be the element and X-ray-phase analyses which have allowed offering the formula for crystal isolated:

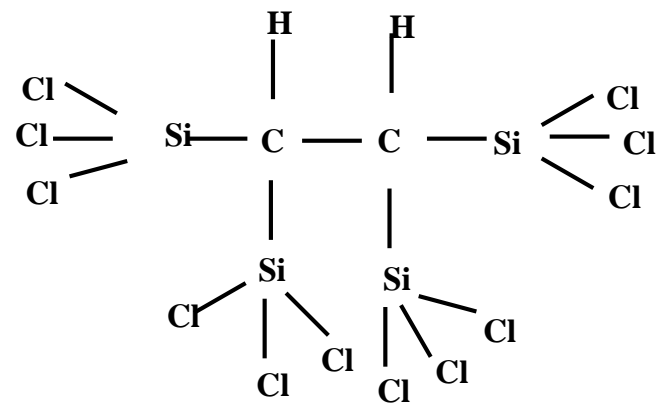

\section{$\mathrm{C}_{2} \mathrm{H}_{2} \mathrm{Si}_{4} \mathrm{Cl}_{12}$}


Table 1. Roentgenography data of chlorosiliconorganic crystal.

\begin{tabular}{cccccc}
\hline $\mathrm{I}, \%$ & $\mathrm{~d}, \AA$ & $\mathrm{hkl}$ & $\mathrm{I}, \%$ & $\mathrm{~d}, \AA$ & $\mathrm{hkl}$ \\
\hline 49 & 3.78 & 111 & 23 & 1.345 & 422 \\
100 & 3.29 & 200 & 4 & 1.270 & 511 \\
100 & 2.33 & 220 & 6 & 1.166 & 440 \\
23 & 1.985 & 311 & 3 & 1.114 & 531 \\
42 & 1.900 & 222 & 12 & 1.099 & 600 \\
51 & 1.646 & 400 & 9 & 1.043 & 6.994 \\
\hline
\end{tabular}

Carbon-silicon bonds are however generally absent in biochemical processes although their fleeting existence has been reported in a freshwater alga. Several organosilicon compounds are being investigated as pharmaceuticals [5].

Organosilyl chlorides are important commodity chemicals. They are mainly used to produce silicone polymers. Especially important silyl chlorides.

It is considered, that the compounds containing bonds Si-Cl are more active, than the compounds containing bonds Si-C. Such bonds are more polar linkages [4].

RPA analysis has shown, that interatomic distances in the crystal investigated is equal to $3 \AA$, that is a characteristic feature of the cluster metal compounds [13].

In our opinion, the crystal isolated by us can be attributed to liquid crystals because of its structure changes under a microscope: as though "is floating”.

In the literature we have met works on synthesis of structures of chlorsilicon organic compounds: $\mathrm{HC}_{2} \mathrm{Si}_{3} \mathrm{Cl}_{3}$, $\mathrm{H}_{3} \mathrm{C}_{2} \mathrm{Si}_{3} \mathrm{Cl}_{9}, \mathrm{C}_{2} \mathrm{Si}_{4} \mathrm{Cl}_{12}$ [14]. There are also works on synthesis of more simple structures, silagraphen, $\mathrm{SiC}_{2}$ [15] and chlorographen, $\mathrm{Si}_{2} \mathrm{Cl}_{6}[16]$.

As to history creation of silagraphen. The first computer modelling of structures has originally been performed. Then one from the set of structures $\left(\mathrm{Si}_{2} \mathrm{C}\right)$ has been chosen and synthesized. The following investigations of its properties has allowed to use these group of compounds under the general name siloxanes in medicine. It has appeared, that silagraphene shows fine elastic properties and it is allowed to use its in manufacturing nanotubes.

As to chlorographen it also has been synthesized. Chlorographens with different degree of chlorination have been received. Their properties, in particularly the influence of different temperatures (from minus to positive) on chlorographen structures have been also determined.

It should be noticed that the compound presented by us does not obtained by chemical synthesis but was isolated from natural object. The substance has been obtained from the representative of the sea invertebrate Ascidians.

The structure offered by us seems to be rather unusual for substances isolated from the animal objects because of it contained the structural elements of the both compounds: namely silagraphen and chlorographen.

\section{Conclusion}

Thus we have managed to isolate from the natural source, namely marine Ascidia, a novel chlorosiliconorganic compound as a crystal form. The element and X-ray-phase analyses of this crystal have allowed us to offer its formula $-\mathbf{C}_{2} \mathbf{H}_{2} \mathbf{S i}_{4} \mathbf{C l}_{12}$. Although the function of this compound isolated within the metabolism of the animal cells has not been cleared this time, the well known properties of synthetic chlorosilanes in time to be a group of compounds widely are used in many chemical processes. Each such compound has at least one silicon-chlorine bond. Organic chlorosilanes are usually used as coating for silicon and glass surfaces, and in the production of silicon (polysiloxane) polymers.

\section{References}

[1] Mischenko, T.Ya., Korotchenko, O.D. and Isay, S.V. (1982) Search for Prostaglandin-Like Substances in Marine Or- 
ganisms. Bulletin of Experimental Biology and Medicine, 94, 94-96.

[2] Rochow, E.G. (1945) The Direct Synthesis of Organosilicon Compounds. Journal of the American Chemical Society, 67, 963-965. http://dx.doi.org/10.1021/ja01222a026

[3] Brook, M.A. (2000) Silicon in Organic, Organometallic, and Polymer Chemistry. John Wiley \& Sons, New York, 704pp.

[4] Bains, W. and Tacke, R. (2003) Silicon Chemistry as a Novel Source of Chemical Diversity in Drug Design. Current Opinion in Drug Discovery \& Development, 6, 526-543.

[5] Colvin, E.W., Baldwin, J.E. and Buckommgham, A.D. (2013) Silicon in Organic Synthesis: Butterworths Monographs in Chemistry. Science, New York.

[6] Price, C.T., Koval, K.J. and Langford, J.R. (2013) Silicon: A Review of Its Potential Role in the Prevention and Treatment of Postmenopausal Osteoporosis. International Journal of Endocrinology, 2013, Article ID: 316783. http://dx.doi.org/10.1155/2013/316783

[7] Burzynski, S. (2012) Novel Cancer Research and Fight to Prove Its Worth. Alternative Therapies in Health and Medicine, 18, 54-61.

[8] Kipping, F. and Lloyd, L.L. (1901) Organic Derivatives of Silicon. Triphenylsilicon and Alkoxysilicon Chlorides. Journal of the Chemical Society, Transactions, 79, 449. http://dx.doi.org/10.1039/ct9017900449

[9] Briquet, F., Colas, A. and Thomas, X. (1996) Silicones for Medical Use. Conf. 20-21 March 1996, France.

[10] Murakami, K., Yorimitsu, H. and Oshima, K. (2010) Synthesis of Tetraorganosilanes: (Chloromethyl)Dimethylphenylsilane. Organic Syntheses, 87, 178. http://dx.doi.org/10.1002/0471264229.0s087.19

[11] Colas, A. and Curtis, J. (2004) Silicones Biomaterials: History and Chemistry. Biomaterials Science: An Introduction to Materials in Medicine, 2, 80-85.

[12] Moretto, H.-H., Schulze, M. and Wagner, G. (2015) “Silicones” in Ulmann’s Encyclopedia of Industrial Chemistry. Wiley-VcH, Weinheim.

[13] Gubin, S.P. (1987) Chemistry of Clusters. Bases of Classification and a Structure. Science, Moscow.

[14] Rudinger, Ch., Beruda, H. and Schmidbaur, H. (1994) Synthesis and Molecular Structure of Silylated Ethenes and Acetylenes. Zeitschrift für Naturforschung, 49b, 1348. http://dx.doi.org/10.1515/znb-1994-1008

[15] Li, Y.F., Li, F.Y., Zhou, Z. and Chen, Z.F. (2011) $\mathrm{SiC}_{2}$ Silagraphene and Its One-Dimensional Derivatives: Where Planar Tetracoordinate Silicon Happens. Journal of the American Chemical Society, 133, 900. http://dx.doi.org/10.1021/ja107711m

[16] Tillmann, J., Meyer, L., Schweizer, J.I., Bolte, M., Lamer, H.-W., Wagner, M. and Holthausen, M.C. (2014) Chloride-Induced Aufbau of Perchlorinated Cyclohexasilanes from $\mathrm{Si}_{2} \mathrm{Cl}_{6}$ : A Mechanistic Scenario. Chemistry-A European Journal, 20, 9234. http://dx.doi.org/10.1002/chem.201402655 